\title{
LA ENTIDAD EMPLEADORA COMO GARANTE DE LOS DERECHOS LABORALES EN LA INVERSIÓN EXTRANJERA*
}

\author{
Maiyolis Mustelier SuÁrez \\ Grisel de la C. Santos Domínguez \\ Abogadas
}

\section{INTRODUCCIÓN}

Con la promulgación del Decreto-Ley 50 de fecha 15 de febrero de 1982, para las Asociaciones Económicas con Capital Extranjero surge en Cuba, en 1982, el concepto de entidad empleadora. Con la creación de empresas mixtas con personalidad jurídica propia y al aceptarse la presencia de empresas de capital totalmente extranjero, se desarrolla en la década de los 90 la entidad empleadora y por analogía se extiende su funcionamiento a las Sociedades Privadas $100 \%$ cubanas.

La necesidad de lograr mayor desarrollo económico en el país, hizo inevitable impulsar y fortalecer la presencia del capital extranjero para el redimensionamiento de la economía nacional, lo que condujo a la introducción de modificaciones en el tratamiento a la participación de capital extranjero en asociación con el capital cubano. Es así que, el 6 de septiembre de 1995 se publicó en la gaceta Oficial y entró en vigor la Ley No 77 de Inversión Extranjera, que contiene su régimen jurídico y en relación con ello se modifica la legislación complementaria con la promulgación de la Resolución No. 3 de 1996 del Ministerio del Trabajo y Seguridad Social, para regular el régimen jurídico-laboral.

La nueva Ley en su Capítulo XI dispone el Régimen laboral para las relaciones jurídicas que se establezcan entre los trabajadores y las empresas mixtas así como con las empresas de capital totalmente extranjero, tienen como norma la intervención del estado en la figura de la "entidad empleadora", a diferencia de los contratos de asociación económica internacional, en los que no existe intermediario pues según establece la propia Ley, las personas que presten sus servicios a las partes en los contratos de asociación económica internacional son contratadas por la parte cubana, con arreglo a las disposiciones legales vigentes en materia de contratación laboral.

Con posterioridad se promulga el Decreto-Ley 165 de 1996 sobre las Zonas Francas y Parques Industriales, y se mantiene el concepto de la intervención de la entidad empleadora para la gestión de la fuerza de trabajo y la participación de los trabajadores en las relaciones laborales, amparadas en el Reglamento puesto en vigor por la Resolución No 20 de 2004 del Ministerio de Trabajo y Seguridad Social.

En tal sentido y por lo antes mencionado, es un objetivo del presente trabajo analizar tanto los aspectos teóricos como lo regulado en la ley y la práctica de los últimos años en el tema de la relación laboral con la participación de la entidad empleadora como intermediaria, valorando las garantías de la protección otorgada a los trabajadores.

Las relaciones jurídicas laborales son aquellas que se establecen entre la dirección de la empresa y los trabajadores, con motivo de la participación de estos en el proceso productivo o de

* Ponencia presentada en el marco del XIX Congreso Iberoamericano de Derecho del Trabajo y de la Seguridad Social. 
Maiyolis Mustelier Suárez y Grisel de la C. Santos Domínguez / La entidad empleadora como garante

de los derechos laborales en la inversión extranjera

prestación de un servicio. Estas relaciones son, básicamente, bilaterales, pero con la intervención de la Entidad empleadora, se forma un "triángulo", lo que convierte la típica relación laboral de bilateral a triangular. La entidad empleadora es el tercer elemento que aparece como intermediario en las relaciones entre el receptor de la mano de obra, llámese el cliente o el usuario y los trabajadores y juega un papel importante en las múltiples actividades en que interviene.

Según la Ley No 77 de 1995, por "entidad empleadora" debe entenderse: "la organización cubana con personalidad jurídica facultada para otorgar con una empresa mixta o de capital totalmente extranjero, un contrato mediante el cual le facilitará a su solicitud, los trabajadores de distintas calificaciones que necesite, quienes mantendrán su vínculo laboral con dicha organización".

Se considera que el estado interviene de cualquier forma en este tipo de relaciones, fundamentalmente con un matiz político de protección de los derechos de los trabajadores, teniendo en cuenta que la empleadora es cubana y es obligatoria su actuación en las relaciones jurídicas donde aparezca una inversión extranjera.

La entidad empleadora aparece sólo por autorización expresa del Ministerio del Trabajo previa propuesta del Ministerio de la Inversión Extranjera. Esta entidad es ajena a la empresa mixta con personalidad jurídica o la de capital $100 \%$ extranjero, y su objeto fundamental es la protección de las relaciones jurídico-laborales.

La ley establece que para los contratos de asociación económica internacional, la parte cubana será quien contrate el personal necesario con arreglo a las disposiciones legales vigentes en materia laboral. En este supuesto, la empleadora está dentro de la propia productora o comercializadora de servicios, en virtud de que dicho contrato no da nacimiento a una entidad con personalidad jurídica propia y diferente a los socios que han aportado el capital, la tecnología o el mercado para el negocio.

Para la actividad petrolera se autorizó como intermediaria una entidad empleadora aún en los casos en que la inversión extranjera se trata de un contrato de asociación económica internacional, para lo cual debe cumplimentarse todo lo dispuesto en ley como si se tratare de una empresa mixta o de capital totalmente extranjero.

La Resolución № 23 de 2003 del MTSS complementaria de la Ley № 77 de la Inversión Extranjera, concretamente expresa que existen "relaciones individuales de trabajo entre los trabajadores y las entidades empleadoras".

Entre los diferentes tipos de entidades con inversión extranjera y los trabajadores no existe una relación jurídico-laboral, sino una prestación de servicios que se hace efectiva por el Contrato de Suministro de Fuerza de Trabajo que inicialmente concierten éstas y la entidad empleadora, mediante el cual la entidad empleadora le facilitará a su solicitud los trabajadores de distintas calificaciones que necesite, tanto para el sector productivo, como de los servicios, los que mantendrán su vínculo laboral con la empleadora y no con las empresas que tienen inversión extranjera.

\section{DIFERENTES TIPOS DE INTERVENCIÓN EN EL EMPLEO DE UNA ENTIDAD EMPLEADORA}

Al momento, en el país hay diferentes experiencias más o menos similares, pero con rasgos distintivos:

- $\quad$ La entidad empleadora de una empresa mixta

- $\quad$ La entidad empleadora de una empresa $100 \%$ extranjera 
- $\quad$ La entidad empleadora para sucursales de firmas extranjeras y agencias de prensa.

- $\quad$ La entidad empleadora para embajadas, consulados y agencias de aviación

- $\quad$ La entidad empleadora de una empresa privada 100\% cubana.

- $\quad$ La entidad empleadora de los cubanos que son contratados por entidades extranjeras para laborar en el exterior.

La entidad empleadora de Zonas Especiales de Desarrollo.

La agencia empleadora para los buques mercantes, de pesca y cruceros.

Oficinas de Empleos para las Organizaciones Económicas del Sistema Empresarial Gaviota S.A.

Agencias Empleadoras para las Unidades bajo administración Extranjera de la sociedad Gaviota S.A.

Los ejemplos que pueden mencionarse para cada una de las tipicidades antes referidas son, entre otros, ACOREC S.A., CUBALSE, UNECA, CUBATECNICA, GÜINCHO CREWING AGENCY, SELECMAR, CUBANACAN, PETROEMPLEO.

ACOREC s.a. (Agencia de Contratación a Representaciones de Firmas Comerciales Extranjeras): Se determina por la Resolución 11 de 2000 del MTSS que esta entidad emplee fuerza de trabajo para las firmas comerciales extranjeras acreditadas en Cuba con las cuales concierta un "contrato de prestación de servicios denominado de suministro de fuerza de trabajo". Para llevar a cabo su función gestiona la fuerza de trabajo y la mantiene en una "bolsa" para que acceda al empleo cuando haya alguna solicitud.

Es una empleadora que sólo funge como tal sin otras actividades en su razón social. Paga los haberes, aplica la legislación laboral y de seguridad social vigente y se responsabiliza con los trabajadores, durante la vigencia del contrato de trabajo, que siempre será a tiempo determinado. A diferencia de lo que establece la Resolución 23 de 2003 del MTSS, no se paga indemnización al trabajador ni se cobra de la usuaria, cuando la empleadora termina la relación laboral por pérdida de la idoneidad.

ECUSE (Empresa Cubana de Servicios): Entidad empleadora de la fuerza de trabajo para la Corporación Cimex. Se ocupa de la selección, preparación y remisión del personal al amparo del Decreto-Ley 55 de 1982. Tiene una reserva de fuerza de trabajo en una "bolsa". Además de la función empleadora, ECUSE tiene otras actividades, lo que significa que no es únicamente la actividad empleadora la que desarrolla.

AGEMARCA (Agencia Empleadora Mar Caribe): Básicamente se desempeña como la empleadora de tripulantes para buques nacionales. Prepara el personal y lo mantiene como reserva listo para su contratación. Establece contrato con las navieras. Aunque no exista un elemento extranjero en la relación jurídica, la empleadora funciona como facilitador de los vínculos con el armador o el fletador del buque y los trabajadores.

GÜINCHO CREWING AGENCY Y SELECMAR: Son las agencias de corretaje de tripulaciones para los armadores extranjeros, sean buques mercantes o cruceros, estableciendo sus relaciones directamente con los trabajadores o a través de las entidades en las que ellos se desempeñan. No tienen contrato de suministro de fuerza de trabajo, firman un contrato económico o comercial individual con el armador por cada trabajador que le suministra, y con el trabajador firman un documento con características que lo diferencian del típico contrato de trabajo, ya que las relaciones laborales se tutelan por la lex loci laboris, o sea, la ley del armador o del pabellón del buque. En los casos de trabajadores que pertenezcan a una empresa, además de los requisitos anteriores, firman un contrato económico con dicha empresa cuyo objeto es la utilización del trabajador para lo solicitado por el armador o fletador del buque. 
Maiyolis Mustelier Suárez y Grisel de la C. Santos Domínguez / La entidad empleadora como garante de los derechos laborales en la inversión extranjera

CUBALSE: Además de todas las funciones que realiza para dar servicio al cuerpo diplomático y otras que la ley expresamente le asigna, tiene una dependencia que selecciona, evalúa, reubica y capacita al personal para sí y para el cuerpo diplomático, consular, agencias de prensa y organizaciones internacionales, e igualmente dota de personal a las firmas comerciales extranjeras que representa. Tiene una bolsa de reserva. Al igual que Acorec S.A., su basamento legal está en el Decreto Ley 55 de 1982 y la Resolución No 3 de 1994 que es el reglamento de las relaciones jurídico-laborales de Cubalse.

CUBANACAN: En su gerencia de Recursos Humanos reúne en sí 2 formas de agencia empleadora: para las firmas comerciales extranjeras que representa y para el personal que labora en su cadena en entidades con participación extranjera en contratos de administración y otros.

ENTIDAD EMPLEADORA DE ZONAS ESPECIALES DE DESARROLLO: Puede ser tanto el concesionario de capital cubano o mixto respecto a los trabajadores requeridos por los operadores como la entidad propuesta por el MINVEC y aprobada por el MTSS que realiza tales funciones para los concesionarios y operadores cuyos capitales sean totalmente extranjeros. Se basa en el Decreto-Ley 165 de 1996 de Zonas Francas y Parques Industriales y la Resolución 20 de 2004 del MTSS, que establece que ninguna persona puede prestar servicios al Operador si no ha establecido previamente su relación laboral con la entidad empleadora correspondiente. El operador o el Concesionario Extranjero, presenta a la entidad empleadora su demanda de fuerza de trabajo especificando, profesiones, cantidad de trabajadores, características laborales de los mismos y un documento que se denomina "contrato de suministro de fuerza de trabajo", el que contiene los derechos y obligaciones de ambas partes y, en lo que se refiere a pagos e indemnizaciones por el que recibe el servicio, obligaciones que se estipulan en moneda libremente convertible.

El contrato individual de trabajo se concierta por escrito entre el trabajador y la entidad empleadora, el que deberá contener entre otros aspectos el tipo de contrato, señalando si es por tiempo indeterminado o determinado u obra. El salario del trabajador lo paga la entidad empleadora, las medidas disciplinarias por infracciones de la disciplina laboral son aplicadas por la autoridad facultada de la entidad empleadora, aunque ésta en el reglamento interno puede facultar al operador o concesionario extranjero a aplicar alguna de las que no modifiquen el estatus laboral del trabajador. Los conflictos laborales se solucionan e la entidad empleadora de conformidad con lo establecido en la legislación vigente.

OFICINAS DE EMPLEOS: Para las Organizaciones Económicas del Sistema Empresarial Gaviota S.A., en este caso las empresas privadas $100 \%$ cubanas. Estas oficinas tendrán como función principal la de suministrar la fuerza de trabajo, con los requerimientos exigidos, para los puestos de trabajo que demanden las Organizaciones Económicas de Gaviota del territorio donde estén enclavadas, así como, actuar como órgano de gestión de los Recursos Humanos de la Delegaciones donde radican, en este caso son meras "intermediarias", pues se limitan exclusivamente a seleccionar la persona que trabajará en las citadas organizaciones económicas, para lo cual suscriben un "contrato de suministro de fuerza de trabajo".

AGENCIA EMPLEADORA para unidades bajo administración extranjera de la sociedad Gaviota S.A.: Se dispone por la Resolución 190 de 1997 del Presidente de Gaviota S.A. que esta agencia emplee fuerza de trabajo para las Unidades bajo administración extranjera de la sociedad Gaviota S.A. con las cuales concierta un "contrato de suministro de fuerza de trabajo". Para llevar a cabo su función capta y selecciona el personal, formaliza la relación laboral con dicho personal mediante la suscripción del contrato de trabajo correspondiente, aplica la legislación laboral y de seguridad social vigente, paga sus haberes, lo que realiza la agencia empleadora a través de la administración, para lo cual esta última entregará a la agencia empleadora la nómina para el 
pago a los trabajadores el primer día de cada mes y luego de revisarla emite el cheque en moneda nacional.

PETROEMPLEO: Creada para actuar como empleadora de la inversión extranjera en la rama petrolera, suministra fuerza de trabajo a empresas mixtas, empresas de capital totalmente extranjero, a tenor de lo estipulado en la Resolución 23 de 2003 del MTSS y fue autorizada mediante la resolución 175 de 2006 del propio ministerio, a suministrar fuerza de trabajo a los contratos de asociación económica internacional, a pesar de que tanto la Ley 77 como la Resolución 23 de 2003 establecen que "Las personas que presten sus servicios a las partes en los contratos de asociación económica internacional son contratadas por la parte cubana, con arreglo a las disposiciones legales vigentes en materia de contratación laboral", lo que indica que en este tipo de figura de la inversión extranjera no está prevista la intervención de una entidad empleadora.

Para suministrar la fuerza de trabajo solicitada por el cliente, PETROEMPLEO, como entidad empleadora suscribe con éste el correspondiente contrato de suministro de fuerza de trabajo. El objeto social de esta empresa no es sólo el suministro de fuerza de trabajo, sino también la preparación y la realización de trámites migratorios.

Según lo normado por la resolución 23 de 2003, el periodo de prueba para los trabajadores contratados es de 30 a 180 días, establece causales de indemnización de la empleadora al trabajador, la que se calcula en base a los años de servicio que tenga el trabajador en su vida laboral.

Como puede observarse, la entidad empleadora no sólo actúa a tenor de una relación jurídica con elemento extranjero, sino también a partir de otro cuerpo legal para la relación jurídica con entidades cubanas privadas, pero se mantiene el principio de la vigencia de una empleadora que define un "triángulo" en las relaciones laborales entre el trabajador y el usufructuario del servicio.

La entidad empleadora se ocupa de la captación y selección del personal, de la calificación y recalificación de los trabajadores, de su reubicación en otras entidades mientras dure el período de interrupción o cuando sea devuelto por la empresa cliente, en el caso de que el contrato de trabajo sea por tiempo indeterminado, así como del pago de las compensaciones o indemnizaciones según lo previsto en la ley.

Como punto de comparación señalamos que lo típico y universal en todas las entidades empleadoras cubanas es que el trabajador se contrata por ellas, presta sus servicios a un tercero que le paga a la empleadora, en moneda libremente convertible de acuerdo a una tarifa y ésta abona el salario y otras compensaciones al trabajador en moneda nacional, mediante la concertación del contrato de trabajo.

Cualquier tipo de conflicto que surja durante el término del empleo, se resuelve por la empleadora a partir de la fundamentación que aporte el usufructuario del servicio.

Otro rasgo similar entre ellas es que al terminar, por cualquiera de las causas previstas en la ley su servicio en la entidad receptora, el trabajador es devuelto a la empleadora que debe ocuparse del mismo ya sea, mediante la recalificación, reubicación o prescinde expresamente de éste por la rescisión del contrato de trabajo.

\section{CONTRATO DE SUMINISTRO DE FUERZA DE TRABAJO}

El contrato de suministro de fuerza de trabajo constituye el inicio de la prestación de servicios y del proceso productivo. La entidad con inversión extranjera se convierte en el cliente de la entidad empleadora en la relación monetario-mercantil que con ella establece, ambas suscriben un contrato que en algunos casos se le llama de "puesta a disposición" y en otros de "suministro". 
Maiyolis Mustelier Suárez y Grisel de la C. Santos Domínguez / La entidad empleadora como garante

de los derechos laborales en la inversión extranjera

La entidad con inversión extranjera, dígase empresa mixta, empresa de capital totalmente extranjero, contrato de asociación económica internacional, en el caso de la actividad petrolera, zonas especiales de desarrollo (zonas francas y parques industriales) y todas las organizaciones económicas del sistema empresarial Gaviota S.A. (Sistema Empresarial de las Fuerzas Armadas Revolucionarias), suscriben con una entidad empleadora, un Contrato de Suministro de Fuerza de Trabajo, que según la Resolución No 11 de 2000, 23 de 2003, la 20 de 2004, todas del MTSS y la 76 de 1999 del Presidente de Gaviota S.A., debe incluir dentro de sus principales cláusulas:

- $\quad$ Precio de los servicios en divisas convertibles por profesión o cargo solicitados y cubiertos;

- $\quad$ Calificación de la fuerza de trabajo requerida;

- $\quad$ Duración del período de prueba, en la empresa, de cada profesión o cargo;

- Causas por las cuales la empresa puede solicitar la devolución de un trabajador a la entidad empleadora;

- Indemnización en divisas convertibles a la entidad empleadora por devolución de un tra-

bajador;

- $\quad$ Principios generales sobre disciplina y organización del trabajo;

- $\quad$ Sustitución y reemplazo de la fuerza de trabajo;

- $\quad$ Régimen de trabajo y descanso;

- Duración y revisión del contrato.

A nuestro entender, se asimila más a un contrato regido por el derecho económico y en otro caso podría cambiarse por "Contrato de Gestión" debiendo funcionar la Empleadora como una Agencia de Servicios de Empleo que cobre un porcentaje por el servicio que brinda, el cual puede sin necesidad de alterar las tarifas existentes, teniendo en cuenta lo que se cobra por hombre.

\section{RELACIONES ENTRE EL TRABAJADOR Y LA EMPRESA CLIENTE}

El suministro de trabajo es la puesta en acción de una relación entre tres partes: un trabajador, un usuario de su trabajo y un suministrador de ese trabajador. En el suministro de personal una persona o empresa proporciona a otra empresa trabajadores para que presten servicios en ella, pero permaneciendo estos formalmente como empleados de la primera, es decir, de la cedente.

En la relación triangular que se forma, la entidad empleadora es quien más fuertemente se halla atada en términos contractuales, pues debe suscribir dos contratos de naturaleza completamente diferentes, con el trabajador suscribe un contrato eminentemente laboral y con el usuario debe concertar un contrato comercial para la prestación del servicio de suministro de fuerza de trabajo, en tanto las otras dos partes del triángulo sólo realizan un solo contrato y es con la empleadora; no se relacionan entre sí desde el punto de vista contractual, no obstante se suscriben sólo dos contratos, se desenvuelven en el triángulo tres relaciones, entre el suministrador (entidad empleadora) y el usuario, relación comercial, entre el suministrador y el trabajador, relación laboral formal, y entre éste y el usuario, relación laboral real.

A nuestro entender, existe una relación formalizada entre las otras 2 partes del triángulo, argumentando nuestra posición en lo siguiente:

1.- $\quad$ El trabajador cuando pasa a prestar servicios al cliente, se subordina al tiempo de trabajo y descanso de dicha empresa, al régimen disciplinario, recibe los cursos de calificación que allí se imparten, se beneficia de los incentivos que se dispongan y es devuelto a la entidad empleadora por el cliente según las causales establecidas en la ley. Además la empresa usua- 
ria se responsabiliza por la seguridad e higiene del trabajo, la protección individual de cada uno de los trabajadores y les garantiza servicios de alimentación y transporte.

2.- La empresa usuaria paga los salarios, vacaciones, incrementos, pagos adicionales, compensaciones e indemnizaciones que establece la ley, en correspondencia con la tarifa aprobada para cada cargo a la entidad empleadora y ésta paga a los trabajadores contratados y no podrá trabajar en la empresa mixta o la de capital totalmente extranjero un trabajador cubano o extranjero residente permanente, que no haya formalizado su relación laboral contractual con la entidad empleadora.

3.- $\quad$ Mediante el Reglamento Disciplinario Interno la entidad empleadora puede facultar a la empresa cliente a imponer medidas disciplinarias que no modifiquen el estatus laboral del trabajador y, en caso de reclamación de éste último ante el órgano que dirime los conflictos laborales, deberá personarse la autoridad facultada de dicha empresa que impuso la medida junto con la representación de la organización sindical. Es éste un aspecto muy controvertido ya que la ley permite que quien no ha establecido la relación laboral con el trabajador, con independencia del documento que la formaliza, quien no sea el empleador, puede aplicar una medida disciplinaria.

Queda probado que existen vínculos entre estos dos sujetos de tipo individual y cuando se trata de la relación jurídica colectiva, la ley recoge la concertación del Convenio Colectivo de Trabajo entre la entidad empleadora, la empresa cliente y la organización sindical.

\section{PROTECCIÓN DE LOS DERECHOS DE LOS TRABAJADORES DE LA INVERSIÓN EXTRANJERA}

La Ley contempla, sólo por excepción, "la contratación directa de la fuerza de trabajo por la empresa mixta" sin que exista la interposición de la empleadora. Sin embargo, los extranjeros no residentes permanentes en Cuba y los miembros del Órgano de Dirección y Administración de la Empresa Mixta, que son designados por la Junta General de Accionistas, se vinculan laboralmente a ésta por decisión del órgano de dirección, sin participación de la entidad empleadora, debiendo tramitar oportunamente los extranjeros no residentes permanentes su permiso de trabajo.

En nuestra legislación no existen normas jurídicas que regulen el trabajo en el régimen de subcontratación ni se define el concepto de intermediación en el empleo, ya que no contamos con agencias de colocación. La función de empleo se realiza por cada entidad en su área de recursos humanos o a través de Oficinas de Empleo territoriales o mediante los servicios de información que prestan las Oficinas de las Direcciones Municipales de Trabajo del Poder Popular.

La existencia de la entidad empleadora coadyuva en la protección de los derechos de los trabajadores pero independientemente de su presencia, el trabajador estaría siempre protegido por la legislación cubana, ya que cualquier empleador debe guiarse por ésta en su actuar y se le garantiza el pleno disfrute de sus derechos laborales y de seguridad social.

Aunque la ley sea omisa al señalar que se aplican "las disposiciones legales vigentes en materia de contratación laboral", asumimos que cuando se firma un contrato de trabajo, nacen las demás relaciones jurídicas de seguridad social, de protección e higiene del trabajo, de calificación, etc. Además vale la pena mencionar que el artículo 37 establece la intervención del Ministerio del 
Maiyolis Mustelier Suárez y Grisel de la C. Santos Domínguez / La entidad empleadora como garante

de los derechos laborales en la inversión extranjera

Trabajo para dictar cuantas disposiciones complementarias sean necesarias para la mejor aplicación de lo que se dispone en cuanto al Régimen Laboral en la Ley 77.

Como la entidad empleadora surge a partir de la autorización que expresamente entrega la autoridad laboral, que en este caso es el Ministerio de Trabajo y Seguridad Social, no existe ningún temor de que pueda aparecer la figura de la intermediación como tráfico ilegal de mano de obra, o que se pueda atentar contra los derechos de los trabajadores.

En el caso del personal de la alta gerencia, no hay contrato de trabajo sino que la relación laboral surge por designación y se vinculan laboralmente, de forma directa, a la entidad extranjera o a la empresa mixta.

La entidad empleadora cubana amparada en la Ley de Inversiones, tiene, a nuestro entender, como rasgos distintivos determinantes los siguientes:

1.- $\quad$ Se crea para gestionar la fuerza de trabajo, pero continúa participando en las relaciones laborales, aún cuando el trabajador sea contratado por tiempo indeterminado y si la entidad usuaria lo devuelve por una causal de ineptitud, falta de idoneidad u otras que la ley señala, debe ocuparse de la reubicación del trabajador o por su recalificación para que pueda ser reubicado.

2.- $\quad$ No tiene carácter exclusivo de empleadora, sino que puede ser una entidad existente con otras funciones en su objeto social a la que se le autorice la actividad empleadora o una que se crea con la actividad empleadora como su objetivo fundamental pero que se le agregan otras funciones a su objeto social.

3.- $\quad$ Es la única vía para trabajar en la empresa cliente, la cual no tendrá trabajadores nacionales o extranjeros residentes permanentes contratados por otra vía y constituye una violación en materia de contratación laboral la existencia en la empresa usuaria de trabajadores no contratados por la entidad empleadora, lo cual da lugar a la imposición de multas administrativas.

4.- $\quad$ Su acción se mantiene, cuando el trabajador deja de prestar el servicio al receptor de la fuerza de trabajo, la empleadora es quien se ocupa del pago de la indemnización, la reubicación y demás protecciones que la ley ofrece a los trabajadores.

Con independencia de lo explicado con anterioridad, en relación con la protección de los derechos de los trabajadores, se observa que existen diferencias entre las resoluciones 11 de 2000, Régimen Laboral del personal contratado para prestar servicios en sucursales extranjeras, la 20 de 2004 Régimen Laboral para las Zonas Especiales de Desarrollo y la 23 de 2003 Régimen Laboral en la Inversión Extranjera, pues en lo que respecta a la indemnización que debe pagar la entidad empleadora a los trabajadores, en las dos primeras resoluciones una de las causales por las que se paga indemnización es la invalidez del trabajador originada por accidente de trabajo o enfermedad profesional y específicamente en la 11 de 2000, también se indemniza por la invalidez del trabajador originada por enfermedad común, a diferencia de lo que dispone la resolución 23 de 2003, que sólo se indemniza al trabajador cuando se termina su relación laboral por pérdida de la idoneidad y se hace solamente si no es reubicado.

En cuanto a la rama petrolera, como se expuso anteriormente, la contratación laboral de los trabajadores que prestan servicios en la inversión extranjera, también es a través de una entidad empleadora, la cual suscribe el correspondiente contrato de suministro de fuerza de trabajo con empresas de capital totalmente extranjero, con empresas mixtas y con sociedades mercantiles que tienen firmado contrato de asociación económica internacional con la Unión Cubapetróleo, para las cuales no está prevista la intervención de la empleadora, pues según lo estipulado en la Ley 77 de Inversión Extranjera, es la parte cubana en función del negocio conjunto, la que deberá contratar el personal que prestará servicios en dicho contrato. 
Dicha entidad tiene suscrito además contratos de suministro de fuerza de trabajo con compañías de servicios en las que no existe participación cubana, pero está indeterminado su estatus jurídico, según lo establecido en la Ley 77 de Inversión Extranjera, pues no han formado empresas mixtas, no han suscrito contratos de asociación económica internacional y no se les da el tratamiento de Empresas de capital totalmente extranjero, aunque lo son, lo que ocasiona dificultades al momento de formalizar la relación laboral con los trabajadores suministrados, pues en la actualidad la contratación de éstos se realiza a tenor de lo estipulado en la resolución 175 de 2006 del MTSS, que no es para estos trabajadores.

Por la mencionada resolución 175 de 2006, la entidad empleadora formalizará la relación laboral con los trabajadores que laborarán en los contratos de asociación económica internacional utilizando el contrato por tiempo determinado por tres años, el que puede ser prorrogable por tres años más y para ser prorrogado por más tiempo, deberá solicitar la autorización del Ministerio de Trabajo y Seguridad Social. A nuestro criterio esta forma de contratación ocasiona desprotección a los trabajadores, pues se trata de una actividad permanente para la cual debía utilizarse el contrato por tiempo indeterminado, lo que a su vez provoca inseguridad al trabajador, pues no sabe si le será prorrogado su contrato o si se terminará su relación laboral.

Por otra parte, si el trabajador es devuelto por el cliente, simplemente se da por terminada su relación laboral, con la imposibilidad de ser beneficiado por el tratamiento laboral previsto para los trabajadores disponibles, que le garantiza salario por un periodo determinado de tiempo y posibilidades de reubicación laboral, tratamiento que sólo se le otorga al trabajador contratado por tiempo indeterminado.

Otro de los inconvenientes que resulta de la aplicación de la citada resolución 175 y que se traduce en desventajas para los trabajadores, es el hecho de que el trabajador, en su mayoría, proviene de otras empresas del sistema Cubapetróleo, las que deben suspender su relación laboral por el término que dure la contratación con la entidad empleadora y están obligadas a conservarles la plaza, lo que no siempre ocurre por las propias necesidades de la producción y que provoca que al concluir su relación laboral con la entidad empleadora o al ser devueltos por el cliente, deben regresar a su antigua posición que está ocupada por otro trabajador que también tiene una relación laboral por tiempo determinado.

Por otro lado, el trabajador durante el tiempo que labora en la inversión extranjera, como lo dispone la Ley, tiene derecho a ser capacitado y promovido a cargos superiores y cuando termina su relación laboral por transcurso del tiempo establecido en la susodicha resolución o es devuelto, regresa a su anterior plaza sin que se tenga en cuenta la calificación que tiene en el momento de su regreso, lo que implica un retroceso en su vida laboral.

Por todos los elementos anteriormente analizados es que en estos momentos esta Resolución está siendo evaluada para su modificación.

\section{CONCLUSIONES}

1.- La entidad empleadora en representación del Estado es el tercer elemento que aparece como intermediario en las relaciones entre el receptor de la mano de obra, llámese el cliente o el usuario y los trabajadores, interviniendo en las relaciones laborales entre los trabajadores y las empresas en las que estos irán a prestar servicios, puede decirse que existen dos 
Maiyolis Mustelier Suárez y Grisel de la C. Santos Domínguez / La entidad empleadora como garante

de los derechos laborales en la inversión extranjera

empleadores para un mismo trabajador: aquel con el cual concierta el contrato de trabajo y otro donde realiza sus funciones de trabajo.

2.- $\quad$ Las relaciones entre la entidad empleadora y la empresa a que se hace mención en la Ley de Inversiones Extranjeras de 1995, se formalizan a partir de un contrato de suministro de fuerza de trabajo, que tendrá naturaleza económica o mercantil. A través de este contrato se establece que la empleadora facilitará a sus clientes los trabajadores de distintas calificaciones que necesite, tanto para el sector productivo, como de los servicios, los que mantendrán su vínculo laboral con la empleadora y no con las empresas que tienen inversión extranjera. Esta relación laboral entre el trabajador y la empleadora se formaliza mediante el contrato de trabajo, aplicándosele la legislación laboral vigente en Cuba.

3.- La relación entre el trabajador y la empresa "cliente" es básicamente de prestación de servicios. La empresa que se beneficia del servicio prestado usa la fuerza de trabajo, paga a la empleadora por su servicio, así como por la plantilla de trabajadores que requiere para el cumplimiento de los fines para los cuales fue autorizada y les extiende los beneficios y estímulos que entienda conveniente.

4.- $\quad$ En Cuba la empleadora se crea para gestionar la fuerza de trabajo, pudiendo ser una entidad existente con otras funciones en su objeto social; constituyendo la única vía para trabajar en la empresa cliente.

6.- $\quad$ En Cuba, la entidad empleadora además de suministrar el personal que necesita la inversión extranjera, garantiza la protección de los derechos laborales de los trabajadores con la aplicación de la legislación laboral vigente, aunque en algunos casos la realidad demuestra que existen insuficiencias legislativas.

\section{BIBLIOGRAFÍA}

Dávila Díaz, Gregorio. El mercado laboral cubano para las empresas extranjeras. Oficina Económica y Comercial de la Embajada Española en Cuba. S/f.

Guevara Ramírez, Lydia. Acerca de algunas relaciones juridicas de naturaleza mercantil reguladas por la Ley de la inversión extranjera. Tesis, 2006.

Hechavarría, Magdalena; Vergara, Mónica. La Cesión de Trabajadores: Quiebres en el Contrato de Trabajo. S/f.

Rojas Chávez, Armando Mario. "La intermediación laboral”, en: Revista de Derecho no 22, Universidad del Norte, 2004, pp. 167-210.

Legislación consultada:

- Constitución de la República de Cuba, Modificaciones introducidas en julio de 1992.

- Ley 49 Código de Trabajo de Cuba, de 28 de diciembre de 1984.

- Ley No. 77 de 1995 de la Inversión Extranjera.

- Decreto-Ley 55 de 1982 sobre las Representaciones extranjeras y sociedades privadas cubanas.

- Decreto-Ley 165 de las Zonas Francas y Parques Industriales, de 1996. 
- Decreto- Ley 166 de 1996, de las Contravenciones del Sistema de contratación del personal y otras regulaciones laborales.

- Resolución No 11/2000 del MTSS sobre las relaciones laborales del personal que presta servicios en Sucursales de firmas extranjeras y otras normas del contrato de prestación de servicios.

- Resolución No 23/2003 del MTSS reglamento sobre el régimen laboral en la Inversión Extranjera.

- Resolución No 20/2004 del MTSS. Reglamento sobre el régimen laboral en las zonas especiales de desarrollo y el contrato de prestación de servicios.

- Resolución 175 de 2006 del MTSS Autorización para contratar trabajadores por tiempo determinado.

- Resolución 76 de 1999 del Presidente de Gaviota S.A. reglamento de las Oficinas de Empleo.

- Resolución 190 de 1997 del Presidente de gaviota S.A. Reglamento sobre las relaciones laborales entre las unidades bajo administración extranjera de la sociedad Gaviota S.A., los trabajadores que laboran en las mismas y las agencias empleadoras de ésta. 